\title{
Profil Konsepsi Siswa pada Materi Energi Berdasarkan Analisis Four- Tier Diagnostic Test
}

\author{
Haratua Tiur Maria Silitonga ${ }^{1, *}$, Erwina Oktavianty ${ }^{2}$, Hamdani $^{3}$, Dendodi $^{4}$ \\ Universitas Tanjungpura, Pontianak, Indonesia ${ }^{1,2,3}$, SMAS Indonesia Muda, Pontianak, \\ Indonesia $^{4}$ \\ haratua.tiur.maria@fkip.untan.ac.id ${ }^{1}$, erwina.oktavianty@ fkip.untan.ac.id ${ }^{2}$, \\ hamdani@fkip.untan.ac.id ${ }^{3}$, aden.dendodi@gmail.com ${ }^{4}$ \\ ${ }^{*}$ Corresponding author
}

\begin{tabular}{ll}
\hline \hline Kata Kunci: & ABSTRAK \\
Konsepsi Siswa; Energi; Four- & Penelitian ini bertujuan untuk mendeskripsikan pemahaman \\
Tier Diagnostic Test & konseptual siswa tentang energi berdasarkan analisis \\
& instrumen tes empat tingkat. Sampel penelitian ini sebanyak 91 \\
& siswa yang diambil melalui teknik purposive sampling dari \\
& kelas X tiga SMA Negeri di Pontianak. Data dikumpulkan \\
& dengan menggunakan tes diagnostik empat tingkat yang terdiri \\
& dari 12 pertanyaan pilihan ganda. Hasil validasi ahli \\
& menunjukkan bahwa indeks Aiken-v adalah 0,73. Reliabilitas \\
& instrumen sebesar 0,783 dan memiliki tingkat keterbacaan \\
& soal 0,63. Hasil yang diperoleh berdasarkan analisis uji \\
& diagnostik empat tingkat terdiri dari Siswa Paham konsep \\
& $(33,2 \%)$, Paham sebagian (8,7\%), Tidak paham konsep \\
& $(12,6 \%)$, dan Miskonsepsi $(45,4 \%)$. \\
\hline
\end{tabular}

\section{PENDAHULUAN}

Miskonsepsi merupakan salah satu permasalahan yang banyak dialami siswa, sehingga mengganggu keberhasilan siswa dalam belajar fisika, bahkan hasil penelitian menunjukkan bahwa fisika merupakan mata pelajaran yang sulit (Eikici, 2016). Siswa seringkali cenderung membentuk pandangannya sendiri ketika belajar tentang dunia, kemudian membuat pemahaman konsepsi yang salah dan cacat (Gurel, Eryilmaz, \& McDermott, 2015). Miskonsepsi siswa membuat fisika umumnya dianggap sulit bagi sebagian besar siswa (Oktavianty, Haratua, \& Anuru, 2018).

Ada beberapa istilah yang berbeda tentang pemahaman siswa yang salah, seperti miskonsepsi (Eshach, Lin, \& Tsai, 2018) dan model mental (Wuellner, Vincent, \& Felts, 2017). Miskonsepsi dapat mengganggu keberhasilan siswa dalam belajar fisika.

Tes diagnostik digunakan untuk mendiagnosis miskonsepsi siswa (Treagust, 1988). Ada beberapa bentuk tes diagnostik pilihan ganda, yaitu tes diagnostik satu tingkat, tes diagnostik dua tingkat (Widiyatmoko \& Shimizu, 2018), tes diagnostik tiga tingkat (Wiyono, Sugiyanto, \& Yulianti, 2016; Caleon \& Subramaniam, 2010a), dan tes diagnostik empat tingkat (Caleon \& Subramaniam, 2010b). Tes diagnostik pilihan ganda dua tingkat, meminta siswa untuk menjawab dan memberikan alasan untuk mengukur pengetahuan isi dan pengetahuan penjelas siswa. Dolan (2010) menyatakan bahwa sangat sulit untuk membedakan peserta didik yang tidak tahu konsep dan peserta didik yang mengalami miskonsepsi. Sementara itu, tes tiga dan empat tingkat mengukur tingkat kepercayaan 
siswa terhadap kebenaran pilihan yang mereka pilih untuk jawaban dan alasannya (Caleon \& Subramaniam, 2010b).

Tes diagnostik dalam penelitian ini menggunakan tes empat tingkat. Tes ini digunakan untuk membedakan siswa yang mengalami miskonsepsi dengan siswa lain yang kurang pengetahuan dan salah konsep (Gurel, Eryilmaz, \& McDermott, 2015). Tes diagnostik pilihan ganda empat tingkat adalah versi yang disempurnakan dari tes tiga tingkat (Wiyono, Sugiyanto, \& Yulianti, 2016) dengan menambahkan tingkat kepercayaan pada setiap jawaban dan alasan (Caleon \& Subramaniam, 2010b). Penambahan tingkat kepercayaan pada setiap jawaban dan alasan dimaksudkan untuk mengukur perbedaan tingkat pemahaman siswa dan miskonsepsi siswa. Penelitian ini dilakukan untuk mendeskripsikan konsepsi energi siswa dengan menggunakan analisis uji diagnostik empat tingkat.

\section{METODE PENELITIAN}

Metode yang digunakan dalam penelitian ini adalah metode kualitatif. Penelitian ini dilakukan untuk mendeskripsikan konsepsi siswa dengan menggunakan analisis tes diagnostik pilihan ganda empat tingkat. Sampel dalam penelitian ini terdiri dari 91 siswa kelas 10 dari tiga sekolah di Kalimantan Barat.

Instrumen yang digunakan untuk mendiagnosis profil konsepsi siswa adalah tes empat tingkat yang terdiri dari 12 item. Tes diagnostik yang digunakan merupakan hasil pengembangan tes yang telah divalidasi oleh ahli. Reliabilitas tes adalah 0,783 dan keterbacaan pertanyaan adalah 0,63.

Berdasarkan penelitian Caleon dan Subramaniam (2010a) dan dengan interpretasi rubrik Four-Tier Diagnostic test (Caleon \& Subramaniam, 2010b), analisis konsepsi siswa dilakukan menggunakan skor hasil tes siswa. Kombinasi jawaban siswa dapat dilihat pada Tabel 1.

Tabel 1. Kategori Kombinasi Jawaban Siswa

\begin{tabular}{|c|c|c|c|c|}
\hline Kategori & Opsi & $\begin{array}{c}\text { Tingkat } \\
\text { Keyakinan }\end{array}$ & Alasan & $\begin{array}{c}\text { Tingkat } \\
\text { Keyakinan }\end{array}$ \\
\hline Miskonsepsi & Salah & Yakin & Salah & Yakin \\
\hline \multirow{3}{*}{ Salah } & Salah & Yakin & Salah & Tidak Yakin \\
\hline & Salah & Tidak Yakin & Salah & Yakin \\
\hline & Salah & Tidak Yakin & Salah & Tidak Yakin \\
\hline $\begin{array}{l}\text { Sesuai Konsepsi } \\
\text { Ilmiah }\end{array}$ & Benar & Yakin & Benar & Yakin \\
\hline \multirow{11}{*}{$\begin{array}{l}\text { Kurang } \\
\text { Pengetahuan }\end{array}$} & Benar & Yakin & Benar & Tidak Yakin \\
\hline & Benar & Tidak Yakin & Benar & Yakin \\
\hline & Benar & Tidak Yakin & Benar & Tidak Yakin \\
\hline & Benar & Yakin & Salah & Yakin \\
\hline & Benar & Yakin & Salah & Tidak Yakin \\
\hline & Benar & Tidak Yakin & Salah & Yakin \\
\hline & Benar & Tidak Yakin & Salah & Tidak Yakin \\
\hline & Salah & Yakin & Benar & Yakin \\
\hline & Salah & Yakin & Benar & Tidak Yakin \\
\hline & Salah & Tidak Yakin & Benar & Yakin \\
\hline & Salah & Tidak Yakin & Benar & Yakin \\
\hline
\end{tabular}

\section{HASIL DAN PEMBAHASAN}

Penelitian ini melibatkan siswa kelas XI MIA 1 di SMA Negeri 2 Pontianak, kelas X MIA 2 di SMA Negeri 7 Pontianak dan kelas X MIA 2 di SMA Negeri 1 Sambas. Tes diagnostik yang dikembangkan 
dalam penelitian ini adalah tes diagnostik empat tingkat, yang merupakan tes diagnostik pilihan ganda yang terdiri dari empat tingkat. Instrumen tes dilakukan sebanyak 12 soal. Persentase yang digunakan pada setiap kategori adalah jumlah siswa yang mengalami miskonsepsi, tidak paham konsep, paham sebagian, dan yang sesuai dengan konsepsi ilmiah atau paham konsep. Kategori yang dihasilkan berasal dari kombinasi jawaban siswa yang memilih opsi dan penalaran pilihannya. Tes diagnostik pilihan ganda empat tahap merupakan perpanjangan dari tes diagnostik pilihan ganda tiga tahap dengan menambahkan tingkat kepercayaan pada setiap jawaban dan alasan (Caleon \& Subramaniam, 2010b). Hasil analisis data sebagai uji interpretasi dirangkum dalam Tabel 2.

Tabel 2. Intepretasi Jumlah Jawaban Siswa Berdasarkan Hasil Tes Diagnostik Empat Tingkat

\begin{tabular}{ccccc}
\hline No & Miskonsepsi & Salah & Konsepsi Ilmiah & Kurang Pengetahuan \\
\hline 1 & 19 & 2 & 62 & 8 \\
2 & 41 & 10 & 39 & 1 \\
3 & 64 & 10 & 14 & 3 \\
4 & 21 & 4 & 55 & 11 \\
5 & 38 & 20 & 24 & 9 \\
6 & 51 & 12 & 21 & 7 \\
7 & 40 & 16 & 21 & 14 \\
8 & 66 & 7 & 15 & 3 \\
9 & 42 & 16 & 29 & 4 \\
10 & 54 & 15 & 18 & 4 \\
11 & 44 & 20 & 20 & 7 \\
12 & 16 & 6 & 45 & 24 \\
\hline Total & $\mathbf{4 9 6}$ & $\mathbf{1 3 8}$ & $\mathbf{3 6 3}$ & $\mathbf{9 5}$ \\
\% & $\mathbf{4 5 , 4 \%}$ & $\mathbf{1 2 , 6 \%}$ & $\mathbf{3 3 , 2 \%}$ & $\mathbf{8 , 7 \%}$ \\
\hline
\end{tabular}

Berdasarkan hasil penelitian yang dilakukan di tiga sekolah, siswa yang mengalami miskonsepsi sebanyak $45,4 \%$, siswa yang tidak memahami konsep sebanyak $12,6 \%$, dan siswa yang memahami konsep sebesar 33,2\% dan siswa yang paham sebagian 8,7\%. Interpretasi keputusan tingkat jawaban siswa didasarkan pada hasil keputusan tes empat tingkat menurut Amin, Wiendartun, dan Samsudin (2016). Tiga bentuk miskonsepsi yang digunakan dalam soal adalah semakin rendah posisi benda, semakin kecil energi kinetik benda yang bergerak ke atas pada pertanyaan nomor 1, 4 dan 12, energi mekanik suatu partikel selalu berkurang jika energi potensial gravitasinya berkurang $(2,5,7,9,11)$ dan energi kinetik akhir partikel yang dipindahkan bergantung pada bentuk lintasan $(3,6,8,10)$. Dari data tersebut terlihat bahwa soal yang mengungkapkan miskonsepsi terakhir (energi kinetik akhir partikel yang dipindahkan tergantung pada bentuk lintasannya) memiliki miskonsepsi paling banyak. Ada beberapa asumsi siswa tentang konsep tersebut. Mereka beranggapan bahwa lintasan yang lebih panjang akan memiliki energi kinetik yang lebih besar karena waktu yang dibutuhkan untuk mencapai garis finis lebih besar, lintasan yang lebih pendek akan memiliki energi kinetik yang besar karena waktu yang dibutuhkan untuk sampai ke garis finis lebih kecil, lintasan yang curam akan memiliki energi kinetik yang besar karena tidak ada halangan yang menghalangi benda ke garis finish. Siswa juga menganggap bahwa lintasan yang memiliki sudut besar akan memiliki energi kinetik yang besar, dan menganggap lintasan yang memiliki sudut kecil akan memiliki energi kinetik yang besar.

Jumlah siswa yang paling banyak memiliki kesesuaian konsepsi dengan ilmuwan adalah indikator pertama (masalah nomor 1, 4 dan 12). Kombinasi lainnya memberikan informasi tentang siswa yang tidak paham konsep dan paham sebagian. Kombinasi jawaban siswa dapat diungkap dari Gambar 1.

Gambar 1(a) menunjukkan kombinasi pilihan siswa yang mengalami miskonsepsi, (b) tidak paham konsep, (c) paham sebagian, dan (d) sesuai konsep ilmiah. Pada Gambar 1(a), siswa yang mengalami miskonsepsi ditandai dengan jawaban siswa yang konsisten menjawab salah dan disertai dengan tingkat kepercayaan diri siswa yang yakin. Menurut Amin, Wiendartun, dan Samsudin (2016) terdapat perbedaan antara siswa yang mengalami miskonsepsi dan tidak memahami konsep. Interpretasi keputusan tingkat jawaban siswa yang tidak memahami konsep seperti yang ditunjukkan pada Gambar 
1(b). Siswa yang belum memahami konsep ditandai dengan jawaban siswa yang konsisten menjawab salah dan disertai dengan tingkat keyakinan siswa yang tidak yakin pada satu tingkat alasan atau tingkat kepercayaan kedua siswa yang tidak yakin. Perbedaan antara siswa yang mengalami miskonsepsi dengan siswa yang tidak memahami konsep terletak pada tingkat kepercayaan diri siswa tersebut.

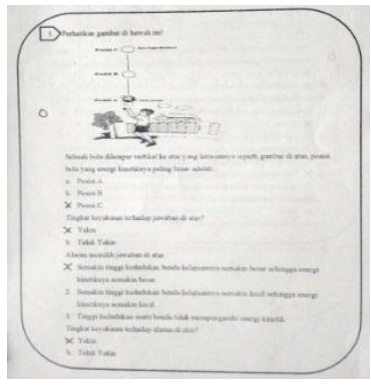

a

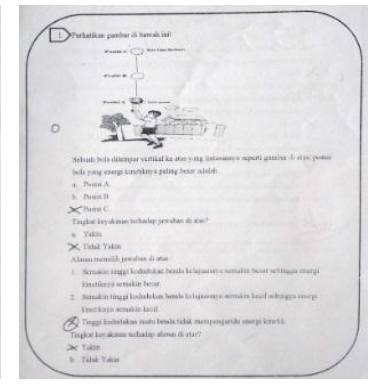

b

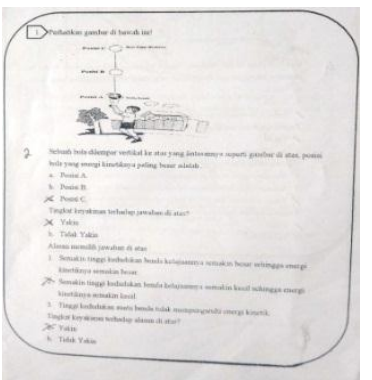

c

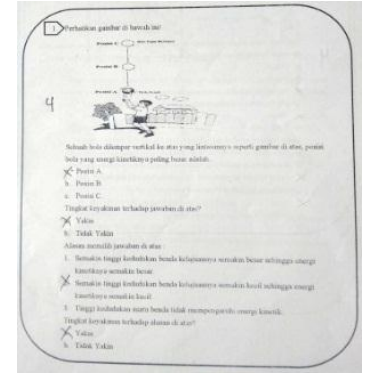

d

Gambar 1. Kombinasi Jawaban Siswa pada Lembar Jawaban: (a) Kombinasi Jawaban Miskonsepsi, (b) Kombinasi Jawaban Tidak Paham Konsep, (c) Paham Sebagian, dan (d) Sesuai dengan Konsepsi Ilmiah

Gambar 1(c) merupakan jawaban siswa yang memahami konsep. Siswa yang memahami konsep ditandai dengan jawaban siswa yang konsisten dalam menjawab jawaban yang benar dan disertai dengan tingkat kepercayaan diri siswa yang yakin. Menurut Amin, Wiendartun, dan Samsudin (2016), ada perbedaan antara siswa yang memahami konsep dan siswa yang memahami sebagian. Gambar 1(d) adalah jawaban siswa yang mengerti. Siswa yang memahami sebagian ditandai dengan jawaban siswa yang konsisten dalam menjawab dengan benar dan disertai dengan tingkat keyakinan siswa yang tidak yakin pada satu tingkat alasan atau kedua tingkat keyakinan siswa yang tidak yakin. Perbedaan antara siswa yang memahami konsep dan siswa yang memahami sebagian terletak pada tingkat kepercayaan diri siswa.

Hasil tes diagnotik four-tier tersebut menunjukkan bahwa instrumen tes dapat digunakan untuk mengidentifikasi konsepsi peserta didik pada materi energi. Sejalan dengan penelitian Fratiwi dkk. (2017), pengidentifikasian konsepsi peserta didik dari tes diagnotik two-tier ke tes diagnostik four-tier pada Hukum Newton menunjukkan hasil bahwa tes diagnostik four-tier akurat untuk mendiagnosis miskonsepsi peserta didik.

\section{KESIMPULAN}

Berdasarkan hasil analisis penelitian, hasil yang diperoleh berdasarkan analisis tes diagnostik empat tingkat terdiri dari siswa yang paham konsep $(33,2 \%)$, paham sebagian $(8,7 \%)$, tidak paham konsep $(12,6 \%)$, dan miskonsepsi $(45,4 \%)$.

\section{DAFTAR PUSTAKA}

Amin, N., Wiendartun., \& Samsudin, A. (2016). Analisis Instrumen Tes Diagnostik Dynamic-Fluid Conceptual Change Inventory (DFCCI) Bentuk Four-Tier Test pada Beberapa SMA di Bandung Raya. Simposium Nasional Inovasi dan Pembelajaran Sains (SNIPS), 570-574.

Caleon, I.S. \& Subramaniam, R. (2010a). Development and Application of A Three-Tier Test to Assess Secondary Students' Understanding of Wafes. International Journal of Science Education, 32(7), 939-961. DOI: https://doi.org/10.1080/09500690902890130

Caleon, I.S. \& Subramaniam, R. (2010b). Do Students Know What They Know and What They Don't Know? Using a Four-Tier Diagnostic Test to Assess the Nature of Students' Alternative Conceptions. Research in Science Education, 40, 313-337. DOI: http://doi.org/10.1007/s11165-009-91122-4 
Dolan, E. (2010). Recent Researh in Science Teaching and Learning. CBE-Life Science Education, 9, 76-77.

Eikici, E. (2016). Why Do I Slog Through the Physics? Understanding HighSchool Students' Difficulties in Learning Physics. Journal of Education and Practice, 7(7), 95-107. Available from: www.iiste.org

Eshach, H., Lin, T.C., \& Tsai, C.C. (2018). Misconception of Sound and Conceptual Change: A Cross-Sectional Study on Students' Materialistic Thinking of Sound. Journal of Research in Science Teaching, 55(5), 664-684. DOI: https://doi.org/10.1002/tea.21435

Fratiwi, N.J., Kaniawati, I., Suhendi, E., Suyana, I., \& Samsudin, A. (2017). The Transformation of Two-Tier Test into Four-Tier Test on Newton's Laws Concepts. AIP Conference Proceedings. https://doi.org/10.1063/1.4983967

Gurel, D.K., Eryilmaz, A., \& McDermott, L.C. (2015). A Review and Comparison of Diagnostic Instruments to Identify Students' Misconceptions in Science. Eurasia Journal of Mathematics, science \& Technology Education, 11(5), 989-1008. DOI: https://doi.org/10.12973/Eurasia.1369a

Oktavianty, E., Haratua, T.M.S., \& Anuru, M. (2018). The Effect of Remediation on Reducing Misconception: A Meta-analysis of Student Thesis on Physics Education. Journal of Physics: Conf. Series, 1013, 012039. DOI: http://dx.doi.org/10.1088/1742-6596/1013/1/012039

Treagust, D.F. (1988). Development and Use of Diagnostic Tests to Evaluate Students Misconception in Science. International Journal of Science Education, 10(2), 159-169. DOI: http://dx.doi.org/10.1080/0950069880100204

Widiyatmoko, A. \& Shimizu, K. (2018). The Development Of Two-Tier Multiple Choice Test To Assess Students' Conceptual Understanding About Light and Optical Instruments. Jurnal Pendidikan IPA Indonesia (JPII), 7(4), 491-501. DOI: http://journal.unnes.ac.id/index.php/jpii Wiyono, F.M., Sugiyanto., \& Yulianti, E. (2016). Identifikation of Motion Misconceptions Analysis Result by Using Three Tier Diagnostic Instruments Among Students on Junior High School. Jurnal Penelitian Fisika dan Aplikasinya (JPFA), 6(2), 61-69. DOI: http://journal.unesa.ac.id/index.php/jpfa

Wuellner, M.R., Vincent, L. \& Felts, B.E. (2017). Environmental Mental Models of College Students. International of Environmental \& Science Education, 12(2), 105-116. 